\title{
Effects of omnivorous filter-feeding fish and nutrient enrichment on the plankton community and water transparency of a tropical reservoir
}

\author{
ROSEMBERG FERNANDES MENEZES, JOSÉ LUIZ ATTAYDE AND FRANCISCO RIVERA \\ VASCONCELOS \\ Centro de Biociências, Departamento de Botânica, Ecologia e Zoologia, Universidade Federal do Rio Grande do Norte, Natal, Rio \\ Grande do Norte, Brazil
}

\begin{abstract}
SUMMARY
1. The major aim of this study was to test the hypothesis that nutrient enrichment and the introduction of the Nile tilapia (Oreochromis niloticus), an exotic omnivorous filter-feeding fish, operate interdependently to regulate plankton communities and water transparency of a tropical reservoir in the semi-arid northeastern Brazil. 2. A field experiment was performed for 5 weeks in 20 enclosures $\left(9.8 \mathrm{~m}^{3}\right)$ to which four treatments were randomly allocated: tilapia addition $(\mathrm{F})$, nutrient addition $(\mathrm{N})$, tilapia and nutrient addition $(\mathrm{F}+\mathrm{N})$ and a control treatment with no tilapia or nutrient addition (C). A two-way repeated measures ANOvA was undertaken to test for time, tilapia and nutrient effects and their interactions on water transparency, total phosphorus and total nitrogen concentrations, phytoplankton biovolume and zooplankton biomass. 3. Nutrient addition had no effect except on rotifer biomass, but there were significant fish effects on the biomass of total zooplankton, copepod nauplii, rotifers, cladocerans and calanoid copepods and on the biovolume of total phytoplankton, large algae $($ GALD $\geq 50 \mu \mathrm{m})$, Bacillariophyta and Zygnemaphyceae and on Secchi depth. In addition, we found significant interaction effects between tilapia and nutrients on Secchi depth and rotifers. Overall, tilapia decreased the biomass of most zooplankton taxa and large algae (diatoms) and decreased water transparency, while nutrient enrichment increased the biomass of rotifers, but only in the absence of tilapia.

4. In conclusion, the influence of fish on the reservoir plankton community and water transparency was significant and even greater than that of nutrient loading. This suggests that biomanipulation of filter-feeding tilapias may be of importance for water quality management of eutrophic reservoirs in tropical semi-arid regions.
\end{abstract}

Keywords: mesocosms, nutrient enrichment, omnivory, Oreochromis niloticus, trophic cascades

\section{Introduction}

Biological communities are regulated simultaneously by consumers and resources, but the relative importance of top-down and bottom-up controls can be highly variable and a major goal of community

Correspondence: José Luiz Attayde, Departamento de Botânica, Ecologia e Zoologia, CB, UFRN, Natal, Rio Grande do Norte, CEP: 59072-970, Brazil. E-mail: attayde@cb.ufrn.br ecology is to understand when, where and why one structuring force is more important than the other. In the pelagic habitats of lakes, it has been hypothesised that the relative importance of top-down (i.e. fish predation) and bottom-up (i.e. nutrient enrichment) controls on plankton would change with latitude, with lower importance of top-down effects at lower latitudes (Lazzaro, 1997; Moss et al., 2004; Stephen et al., 2004; Jeppesen et al., 2007). One argument is that phytoplankton growth would benefit from extended 
growing seasons in warm water lakes and, as phytoplankton growth is faster than that of zooplankton, its growth would rather be controlled by nutrient shortage than by zooplankton grazing at lower latitudes (Moss et al., 2004; Stephen et al., 2004). Another argument is that zooplankton in (sub)tropical lakes, being often dominated by small-bodied species with low grazing pressure, would be less likely to control the development of algal populations than in temperate lakes (Fernando, 1994; Lazzaro, 1987; Jeppesen et al., 2007). Furthermore, the planktivorous fish stock in (sub)tropical lakes is often dominated by omnivorous species that reproduce throughout the year and are neither controlled by zooplankton availability nor by piscivore predation (Fernando, 1994; Lazzaro, 1997; Jeppesen et al., 2007). Therefore, the manipulation of fish communities in (sub)tropical lakes would be less likely to indirectly affect phytoplankton growth. Besides, the response of phytoplankton to this perturbation would be less predictable at lower latitudes due to higher levels of fish omnivory.

Omnivory (i.e. feeding on more than one trophic level) can either increase or decrease the biomass of primary producers depending on the relative strength of the direct and indirect effects of the omnivorous predators (Diehl, 1993). Many (sub)tropical lakes are dominated by omnivorous filter-feeding fish that can affect phytoplankton directly, by selectively consuming larger phytoplankton species (Datta \& Jana, 1998; Turker, Eversole \& Brune, 2003; Hambright, Blumenhine \& Shapiro, 2002; Lu et al., 2006), but also indirectly by suppressing herbivorous zooplankton, resuspending settled phytoplankton or excreting nutrients in dissolved forms into the water column (Stein, DeVries \& Dettmers, 1995; Drenner, Smith \& Threlkeld, 1996; Vanni, 2002). Therefore, while the abundance of large phytoplankton should be inhibited by fish grazing, the abundance of small phytoplankton should be enhanced by filter-feeding fish due to suppression of large phytoplankton, reduction of herbivorous zooplankton and nutrient excretion (Drenner et al., 1996; Figueredo \& Giani, 2005; Okun et al., 2008; Rondel et al., 2008). Hence, the overall effect of filter-feeding fish on total phytoplankton biomass and water transparency can be variable in both strength and direction and depends on the relative strength of these direct and indirect effects.

The strength of planktivorous fish effects on pelagic food webs depends also on lake trophic state (Brett
\& Goldman, 1997; Pace et al., 1999). It has been suggested that the enhancement of phytoplankton biomass by planktivorous fish is stronger in oligotrophic than in eutrophic lakes (McQueen, Post \& Mills, 1986; McQueen et al., 1989). However, other studies have demonstrated that changes in the biomass of planktivorous fish produce the greatest cascading effect on phytoplankton in eutrophic lakes (Perrow et al., 1997; Hansson et al., 1998; Meijer et al., 1999; Pace et al., 1999; Jeppesen et al., 2003). Unfortunately, most work on the interaction between fish and nutrients has focused on visually feeding zooplanktivorous fish and few studies have tried to understand the interaction between nutrients and filter-feeding fish effects on plankton communities (Chumchal \& Drenner, 2004; Drenner et al., 1996, 1998).

Drenner et al. (1996, 1998) hypothesised that filterfeeding omnivorous fish interact synergistically with lake trophic state so that the fish effects on phytoplankton biomass and productivity become more intense with increased eutrophication. One mechanism for the existence of synergistic interactions between omnivorous fish and nutrients is that with simultaneous nutrient loading and zooplankton removal by fish, the phytoplankton can grow at a higher rate and reach higher biomass than in the absence of fish. Another mechanism is that nutrient recycling and translocation from benthic to pelagic habitats by omnivorous fish can increase with lake productivity and further increase phytoplankton biomass (Vanni \& Headworth, 2004; Vanni et al., 2005). However, such synergism between nutrient enrichment and omnivorous fish effects implies that the negative effect of fish grazing on phytoplankton is negligible. If fish grazing on phytoplankton is important one could actually expect an antagonistic or no interaction between nutrients and fish since the positive effect of enrichment on algal biomass would be counteracted by the negative effect of fish grazing. Likewise, an antagonistic or no interaction would be expected between nutrients and fish effects on zooplankton if the negative effects of fish predation on zooplankton are attenuated by increased primary productivity with nutrient enrichment.

The present study aims to test the hypothesis that the effects of nutrient enrichment on phytoplankton biomass are enhanced by omnivorous filter-feeding fish, while the nutrient enrichment effects on zooplankton biomass are inhibited by fish. In other words, we aimed to test the hypothesis that nutrients 
and omnivorous fish interact synergistically to affect phytoplankton and antagonistically to affect zooplankton in a tropical reservoir. We performed a field mesocosm experiment manipulating the presence/absence of the Nile tilapia, Oreochromis niloticus $L$. , at two levels of nutrient loading. The Nile tilapia is a planktivorous fish native to Africa but has been widely introduced to tropical lakes and reservoirs in Asia and America for aquaculture and fisheries purposes. The species is highly invasive (Canonico et al., 2005; Zambrano et al., 2006) and is probably the most widely distributed exotic fish worldwide after common carp (Cyprinus carpio carpio L.). To the best of our knowledge, this is the first experimental study that has investigated the combined effects of omnivorous fish and nutrients on the plankton community of a tropical freshwater system. Since many tropical lakes and reservoirs suffer from eutrophication and introduction of exotic fish like tilapias, it is crucial to understand how omnivorous fish and nutrients may operate interdependently to regulate plankton communities and the water quality of these ecosystems.

\section{Methods}

\section{Study area and experimental design}

The experiment was performed from 4 September to 12 October 2006 in a small and shallow reservoir with an accumulation capacity of $433000 \mathrm{~m}^{3}$ (V.M.A. Medeiros, unpubl. data) situated in Seridó Ecological Station in Serra Negra, Rio Grande do Norte, Brazil $\left(06^{\circ} 34^{\prime} 852^{\prime \prime} \mathrm{N}, 37^{\circ} 15^{\prime} 519^{\prime \prime} \mathrm{W}\right)$. The experiment was carried out in 20 mesocosms with a diameter of $2.5 \mathrm{~m}$ and a height of $2 \mathrm{~m}\left(\right.$ c. $\left.9.8 \mathrm{~m}^{3}\right)$. They were placed side by side along the reservoir shore and had a cylinder shape with an iron frame on the bottom and at the top. The walls were made of transparent plastic (thickness: $0.45 \mathrm{~mm}$ ). The mesocosms were open to the atmosphere and to the sediment but were completely isolated from the surrounding reservoir water.

The experimental design consisted of four treatments: tilapia addition $(\mathrm{F})$, nutrient addition $(\mathrm{N})$, tilapia and nutrient addition $(\mathrm{F}+\mathrm{N})$ and a control treatment with no tilapia or nutrient addition (C). The treatments were replicated five times and randomly allocated in the mesocosms containing the water and natural plankton community of the reservoir. The mesocosms were free of fish and macrophytes from the beginning of the experiment. The fish $(16.59 \pm 7.23 \mathrm{~cm})$ were collected at a fish hatching station $25 \mathrm{~km}$ from the reservoir and stocked in the treatments $\mathrm{F}$ and $\mathrm{F}+\mathrm{N}$ with a density of 1 fish $\mathrm{m}^{-3}$. In the treatments with nutrients, $1.14 \mathrm{~g}$ of $\mathrm{KH}_{2} \mathrm{PO}_{4}$ and $10.88 \mathrm{~g}$ of $\mathrm{NaNO}_{3}$ were added every week to get a final nutrient concentration in the water of the mesocosms of about $100 \mu \mathrm{g} \mathrm{L}{ }^{-1}$ $\mathrm{P}_{-} \mathrm{PO}_{4}$ and $1000 \mu \mathrm{g} \mathrm{L}{ }^{-1} \mathrm{~N}-\mathrm{NO}_{3}$.

The experiment lasted 5 weeks and sampling was performed on the first day, just after the stocking of fish into the enclosures and thereafter once every week. The nutrients were added once every week just after each sampling and the stocked fish were weighted at the start and at the end of the experiment. The variables monitored during the experiment, both in the mesocosms and reservoir, were: species composition and relative abundance of phytoplankton and zooplankton, total phosphorus and total nitrogen concentrations, temperature, dissolved oxygen, $\mathrm{pH}$, turbidity and electric conductivity of the water.

\section{Collection and sample analysis}

The water samples were collected through a $2 \mathrm{~m}$ high PVC channel at three different points in each mesocosm and integrated in a single representative sample, from which subsamples were taken for total nitrogen, total phosphorus and phytoplankton analyses. Zooplankton samples were collected through vertical taws with a plankton net with $20 \mu \mathrm{m}$ mesh size. The taws were done in the center of each mesocosm and the total volume filtered was about $212 \mathrm{~L}$. The phytoplankton samples were fixed with lugol's solution and the zooplankton samples with $4 \%$ formaldehyde. The total phosphorus analysis was done according to the ascorbic acid method after persulphate digestion (APHA 1997), while total nitrogen was analysed as nitrate by the sodium salycilate method (Muller \& Weidemann, 1955) after persulphate digestion in alkaline medium (Valderrama, 1981). The temperature, $\mathrm{pH}$, electric conductivity and oxygen concentrations were measured through a multiparameter analyser U-22 HORIBA (Kyoto, Japan). The water transparency was measured with a Secchi disc.

The zooplankton organisms were counted under a microscope in a $1 \mathrm{~mL}$ Sedwick-Rafter chamber. Between three and five subsamples were counted for each sample collected in the field until a minimum of 
100 individuals of each taxonomic group had been counted. Subsequently, the average of the subsamples was taken for each group of organisms counted, this being multiplied by the sample volume $(\mathrm{mL})$ and divided by the subsample volume $(1 \mathrm{~mL})$ to estimate the total number of individuals in the sample. Afterwards, the number of individuals in the sample was divided by the water volume (L) sampled in the field to calculate the original density (ind. $\mathrm{L}^{-1}$ ) of organisms in the sample. For estimating zooplankton biomass at least 30, randomly chosen individual were measured, from the most abundant species. For rotifers geometrical formulae were used to estimate biovolume (Ruttner-Kolisko, 1977). Wet weight was estimated from the biovolume of each individual, assuming that $10^{6} \mu \mathrm{m}^{3}$ corresponds to $1 \mu \mathrm{g}$ of wet weight. Dry weight was estimated as 10\% of wet weight (Pace \& Orcutt, 1981). Microcrustacean biomass (copepods and cladocerans) was estimated using regression equations relating dry weight and body length according to Bottrell et al. (1976).

The phytoplankton was quantified according to Utermöhl's method (Utermöhl, 1958) under an inverted microscope. Before counting, the samples were allowed to sediment for $3 \mathrm{~h}$ for each centimetre height of the chamber (Margalef, 1983). The individuals (cells, colonies and filaments) were enumerated in random fields as proposed by Uhelinger (1964), with an error smaller than $20 \%$ and a confidence interval of 95\% (Lund, Kipling \& Lecren, 1958). To estimate the phytoplankton biovolume at least 25 individuals from each species were measured by applying approximations to similar geometric solids (Hillebrand et al., 1999).

\section{Statistical analysis}

A two-way repeated measures ANOVA, with two levels of nutrients, two levels of fish and five samples collected in each experimental unit was done to test the separated effects of tilapias $(\mathrm{F})$, nutrients $(\mathrm{N})$, time $(t)$ and the interaction effects among these factors $(\mathrm{F} \times \mathrm{N} ; t \times \mathrm{N} ; t \times \mathrm{F} ; t \times \mathrm{N} \times \mathrm{F})$ on total nitrogen and phosphorus concentrations and ratio, on phytoplankton biovolume, zooplankton biomass and water transparency. A two-way ANOvA was done to test for the separated effects of tilapias, nutrients and the interaction effects between these factors $(\mathrm{F} \times \mathrm{N})$ on the size of zooplankton species on the last week of the experiment. A paired $t$-test was used to compare the tilapia biomass at the beginning and end of the experiment. Prior to analyses, data were $\log (x+1)$ transformed to stabilise variances. The significance level assumed was $\alpha=0.05$. All statistical analyses were run with STATISTICA 7.0 (Statsoft, Inc., Tulsa, OK, U.S.A.).

\section{Results}

\section{Abiotic variables}

During the experiment, the average values $( \pm 1$ SD) of water temperature, $\mathrm{pH}$, electric conductivity and dissolved oxygen were $29.62\left( \pm 1.13^{\circ} \mathrm{C}\right), 6.85( \pm 0.67)$, $0.085\left( \pm 0.002 \mu \mathrm{S} \mathrm{cm}{ }^{-1}\right)$ and $5.81\left( \pm 0.68 \mathrm{mg} \mathrm{L}^{-1}\right)$ respectively, across the 20 mesocosms. The above variables were not affected by either fish or nutrients addition (data not shown) and are described here just by their overall average and SD. Results from the two-way repeated measures ANOVA show that there were significant effects of nutrients $(\mathrm{N})$ and tilapias $(\mathrm{F})$ and a significant interaction between these factors $(\mathrm{F} \times \mathrm{N})$ on the water transparency measured by the Secchi depth (Fig. 1). The water transparency was reduced due to tilapia addition independently of the nutrient level while the effect of nutrient addition on water transparency was only evident in the absence of tilapia (Fig. 1). Conversely, no significant effects of nutrients or tilapias nor significant interactions between these factors were found on total nitrogen and phosphorus concentrations and on the ratio between these elements (data not shown). A significant interaction of fish addition with time was found on Secchi depth but not on the concentrations of nutrients (Fig. 2).

\section{Zooplankton biomass}

The zooplankton biomass was dominated by calanoid copepods in all treatments as well as in the reservoir and the genus Notodiaptomus comprised the bulk of the total zooplankton biomass $(>75 \%)$. The main rotifer genera were: Brachionus, Trichocerca, Filinia, Hexarthra and Keratella, while the main genera of microcrustaceans (cladocerans and copepods) were: Moina, Ceriodaphnia, Diaphanosoma, Thermocyclops and the dominant Notodiaptomus.

The two-way repeated measures ANOVA results show that the total biomass of zooplankton and the 

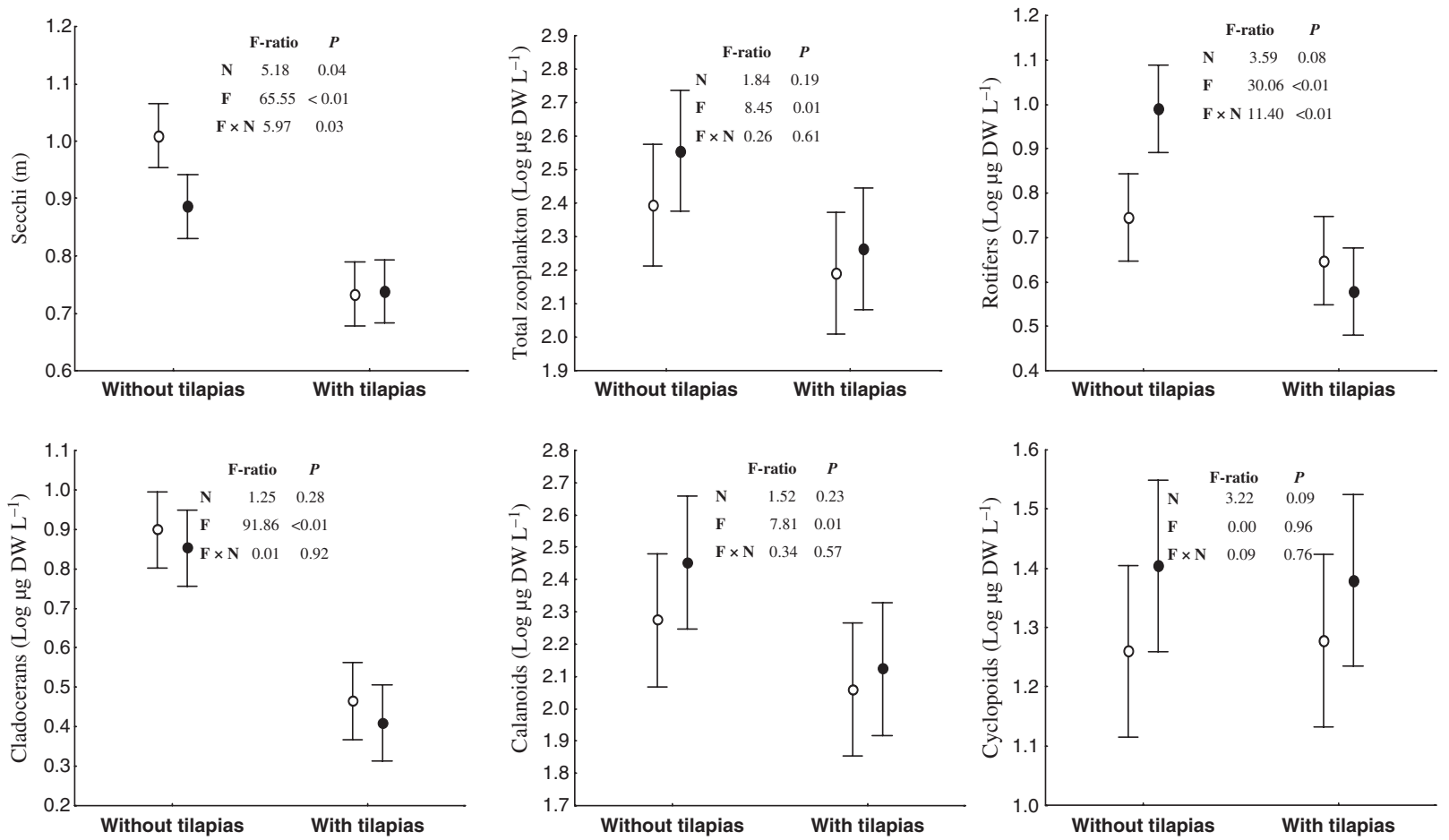

Fig. 1 Results of two-way repeated measures ANOVA to test for the effects of tilapia (F), nutrients (N) and the interaction among these factors $(\mathrm{F} \times \mathrm{N})$ on the water transparency, total zooplankton biomass and the biomass of major zooplankton groups averaged across time. The dots and bars represent the means and standard deviation of treatments with (black) and without (white) nutrient additions. Results shown inside each graph are the F-ratios and $P$-values of the ANova. Values were considered significant assuming $\alpha=0.05$.

biomass of rotifers, cladocerans, calanoid copepods and copepod nauplii were negatively affected by tilapias (Fig. 1). The genera responsible for these significant responses were Filinia, Keratella, Moina and Notodiaptomus (data not shown). However, some effects of tilapia on zooplankton biomass were time dependent (Fig. 3). Nutrient enrichment had no significant effect on zooplankton biomass, but there was a significant interaction between the effects of nutrients and tilapias on rotifers (Fig. 1). The biomass of rotifers increased with nutrient addition but only in the absence of tilapia (Fig. 1). The negative effects of tilapia on copepods and cladocerans biomass were mediated by a decrease in density, because no difference in the individual mean size of the dominant species was found among the treatments (Fig. 4).

\section{Phytoplankton biovolume}

At the beginning of the experiment, the total phytoplankton biovolume in all mesocosms was dominated by cyanobacteria and bacillariophyta. The most representative genera, accounting together for more than $70 \%$ of the total phytoplankton biovolume, were Cylindrospermopsis, Aphanocapsa, Synedra, Aulacoseira, Navicula and Micrasterias. During the experiment, the relative abundance of cyanobacteria (mainly Cylindrospermopsis) increased in the treatments with tilapias and in the reservoir, while the relative abundance of bacillariophyta increased in the treatments without tilapias (data not shown). Results from the two-way repeated measures ANOVA indicate that there were negative effects of tilapia on the total phytoplankton biovolume, on the biovolume of bacillariophyta, zygnemaphyceae and algae with GALD larger than $50 \mu \mathrm{m}$ (Fig. 5), but some of these effects were time dependent (Fig. 6). The genera responsible for these significant responses were mainly Synedra and Micrasterias (data not shown). Conversely, the phytoplankton biovolume did not respond to nutrient enrichment and there was no interaction between the effects of tilapia and nutrients on phytoplankton (Fig. 5). 

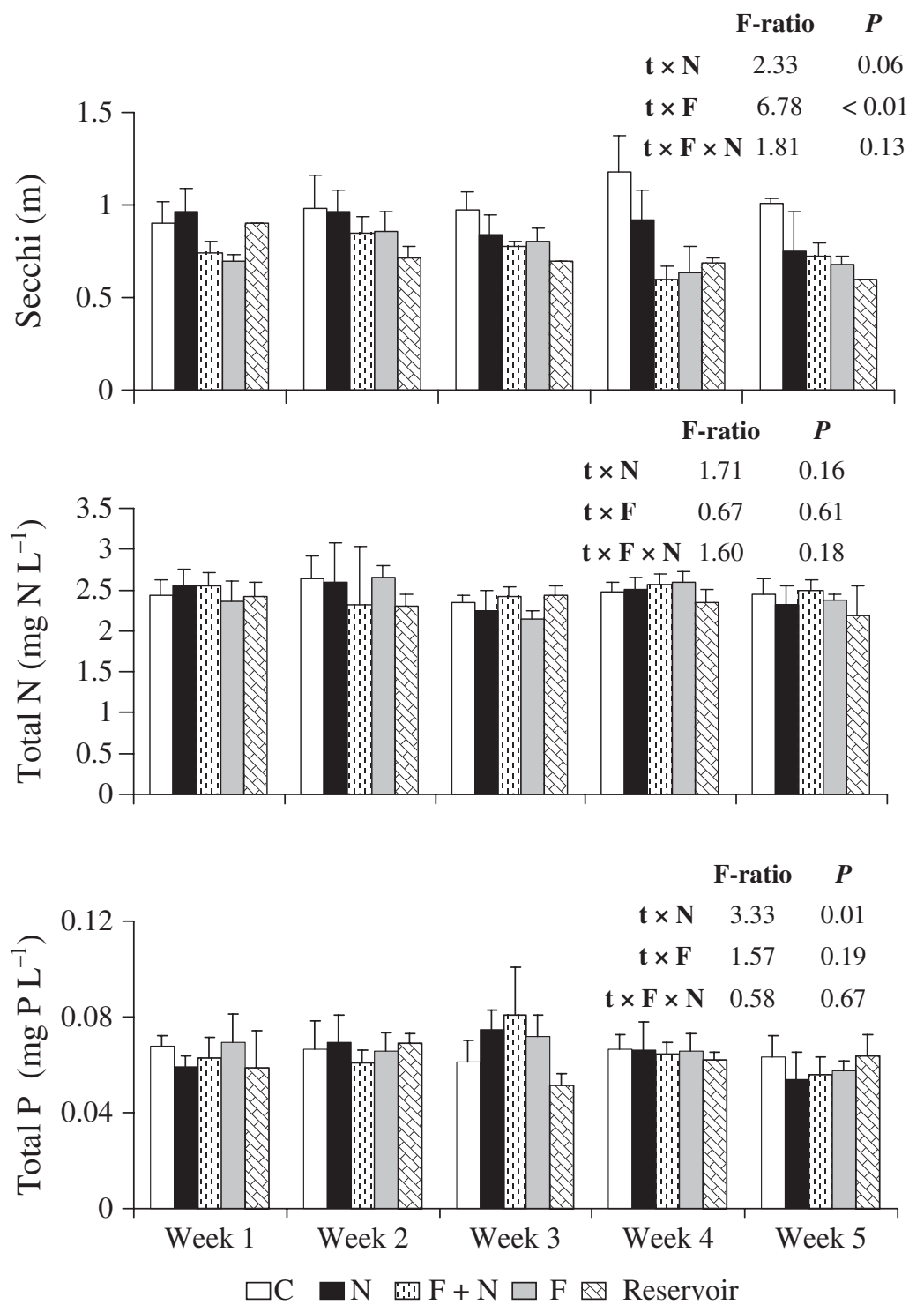

Fig. 2 Average values ( \pm 1 SD) of Secchi depth and total nitrogen and phosphorus concentrations in the experimental treatments and in the reservoir at each sampling week. Results shown inside each graph are the $F$-ratios and $P$-values of the two-way repeated measures ANOVA interaction terms with time $(t)$. Values were considered significant assuming $\alpha=0.05$.

\section{Tilapia biomass}

The tilapia biomass significantly increased during the experiment in both the $\mathrm{F}(t=-6.37 ; P=0.0031)$ and $\mathrm{F}+\mathrm{N}$ treatments $(t=-14.46 ; P=0.0001)$, but no difference was found in the initial $(t=1.8689$; $P=0.098)$ or final $(t=-0.2725 ; P=0.7921)$ biomass between the treatments (Fig. 7).

\section{Discussion}

Our results indicate that omnivorous filter-feeding fish such as the Nile tilapia can reduce both zooplankton and phytoplankton biomass and still

decrease water transparency through mechanisms other than stimulating algal growth. Instead of indirectly enhancing phytoplankton through predation on zooplankton and nutrient excretion, the Nile tilapia reduced the biomass of large algae (GALD $>50 \mu \mathrm{m}$ ) and total phytoplankton biomass through direct grazing. Therefore, this widespread omnivorous fish can affect plankton communities in a different way than visually feeding zooplanktivorous fish. Conversely, nutrient enrichment did not affect the biomass of zooplankton and phytoplankton or the plankton community structure, with the exception of rotifers that were enhanced by enrichment, but only in the absence of tilapias. Contrary to our expectation, 

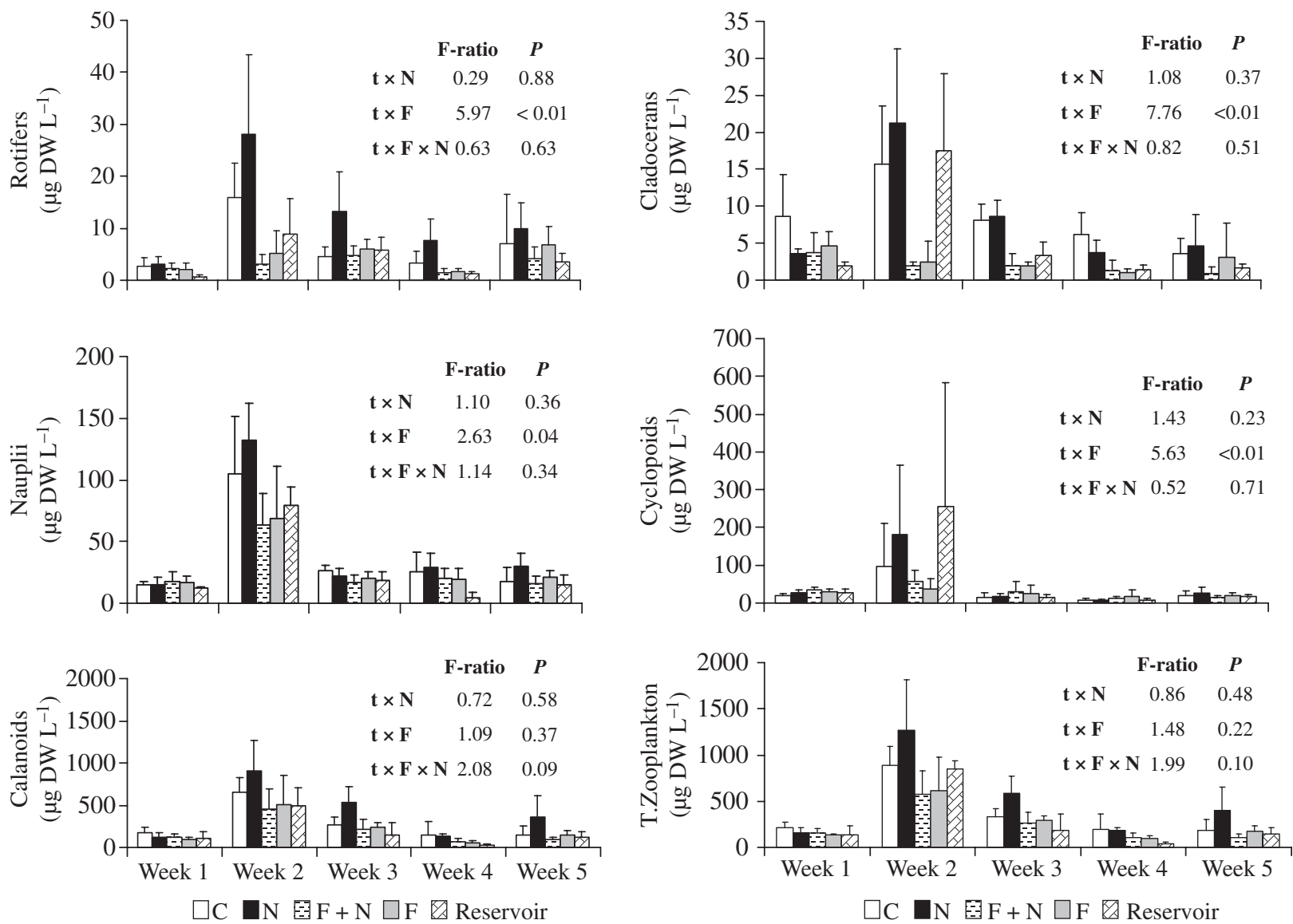

Fig. 3 Average values $( \pm 1 \mathrm{SD}$ ) of zooplankton biomass in the experimental treatments and in the reservoir at each sampling week. Results shown inside each graph are the $F$-ratios and $P$-values of the two-way repeated measures ANOvA interaction terms with time $(t)$. Values were considered significant assuming $\alpha=0.05$.

Fig. 4 Mean length $( \pm 1$ SD) of the larger zooplankton taxa in the four experimental treatments and in the reservoir at the end of the experiment. Results shown inside the graph are the $F$-ratios and $P$-values of the two-way ANOvA.

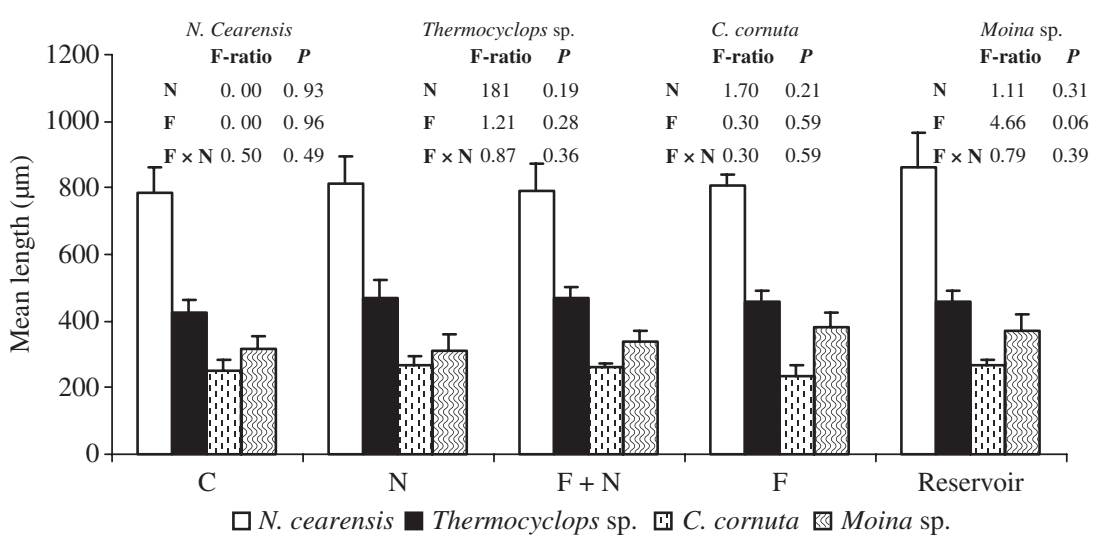

separate effects. Therefore, the picture that emerges from this experiment is that of a strong effect of fish and a negligible effect of nutrients on the plankton community of this small tropical reservoir. This seems except for rotifers we found no significant interactions between the effects of tilapia and nutrients on phytoplankton or zooplankton, suggesting that their combined effects can be predicted as the sum of their (c) 2009 Blackwell Publishing Ltd, Freshwater Biology, 55, 767-779 

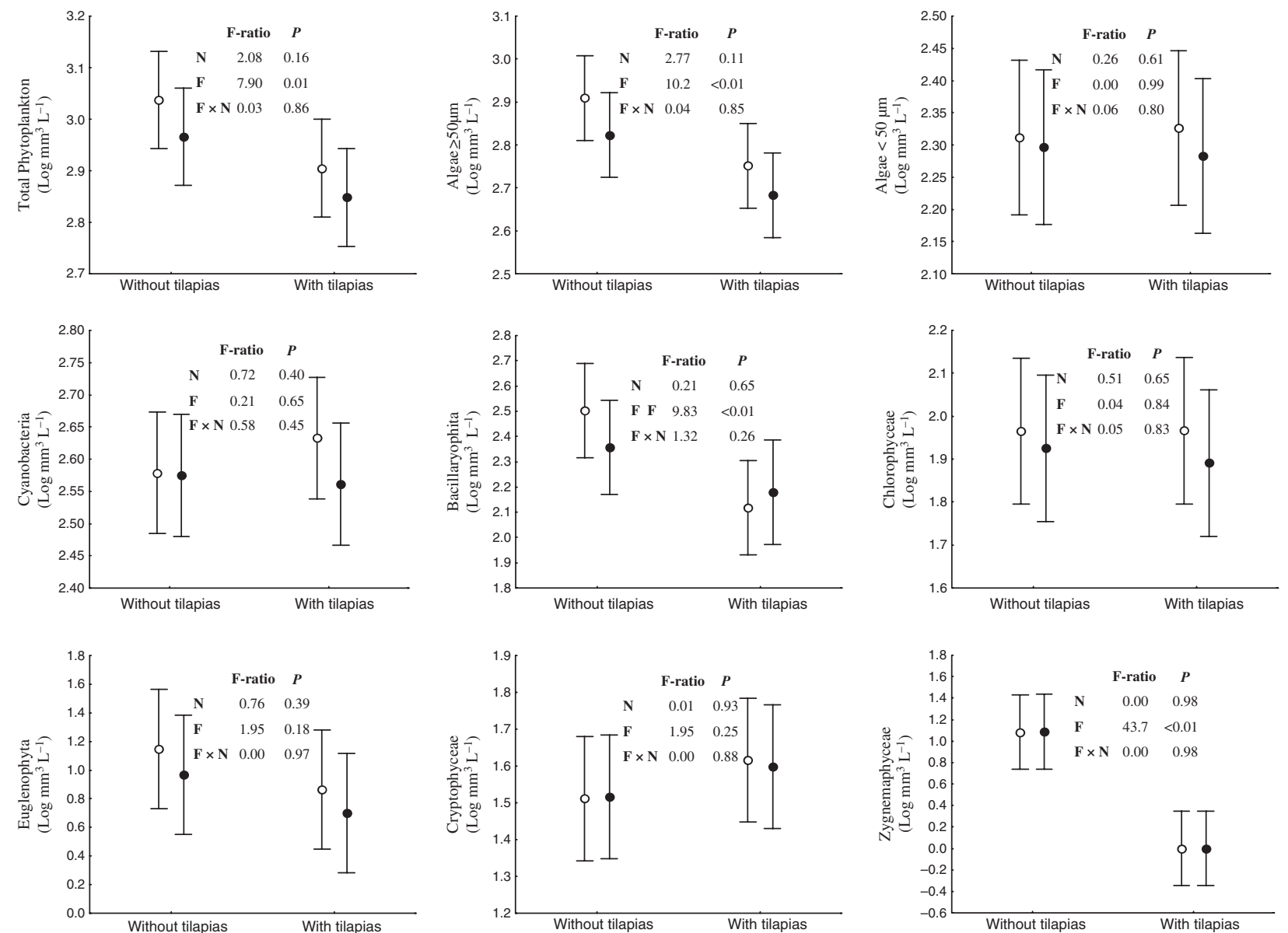

Fig. 5 Results of two-way repeated measures ANOva to test for the effects of tilapia (F), nutrients (N) and the interaction among these factors $(\mathrm{F} \times \mathrm{N})$ on the total phytoplankton biovolume and the biovolume of major phytoplankton groups averaged across time. The dots and bars represent the means and standard deviation of treatments with (black) and without (white) nutrient additions. Results shown inside each graph are the $F$-ratios and $P$-values of the ANOVA. Values were considered significant assuming $\alpha=0.05$.

to contradicts the hypothesis of stronger bottom-up than top-down regulation in warmer lakes and reservoirs (Moss et al., 2004; Jeppesen et al., 2007), but is actually in agreement with the idea that high initial concentrations of nutrients lead to de-emphasis of the importance of nutrient loading in experiments comparable to the present one (Moss et al., 2004).

However, results from previous studies manipulating tilapias suggest that its effects on plankton can be highly variable and context dependent (Diana, Dettweiler \& Lin, 1991; Elhigzi, Haider \& Larsson, 1995; Starling et al., 1998; Figueredo \& Giani, 2005; Attayde \& Menezes, 2008; Okun et al., 2008; Rondel et al., 2008). For example, in a previous experiment carried out in the same reservoir as the one in this study, tilapia selectively consumed large cladocerans and indirectly increased the biomass of edible algae (GALD $\leq 50 \mu \mathrm{m}$ ) in a manner analogous to zooplanktivorous fish but had no effect on total zooplankton or total phytoplankton biomass (Okun et al., 2008). The contrasting results from these two mesocosm experiments in the same system indicate that fish effects can be highly variable from 1 year to another and that experiments need to be repeated more frequently for good understanding of the relative importance of different processes regulating community structure in (sub)tropical as in temperate systems (Moss et al., 2004).

Attayde \& Menezes (2008) hypothesised that the size structure of the phytoplankton community may influence the outcome of experiments manipulating

(C) 2010 Blackwell Publishing Ltd, Freshwater Biology, 55, 767-779 

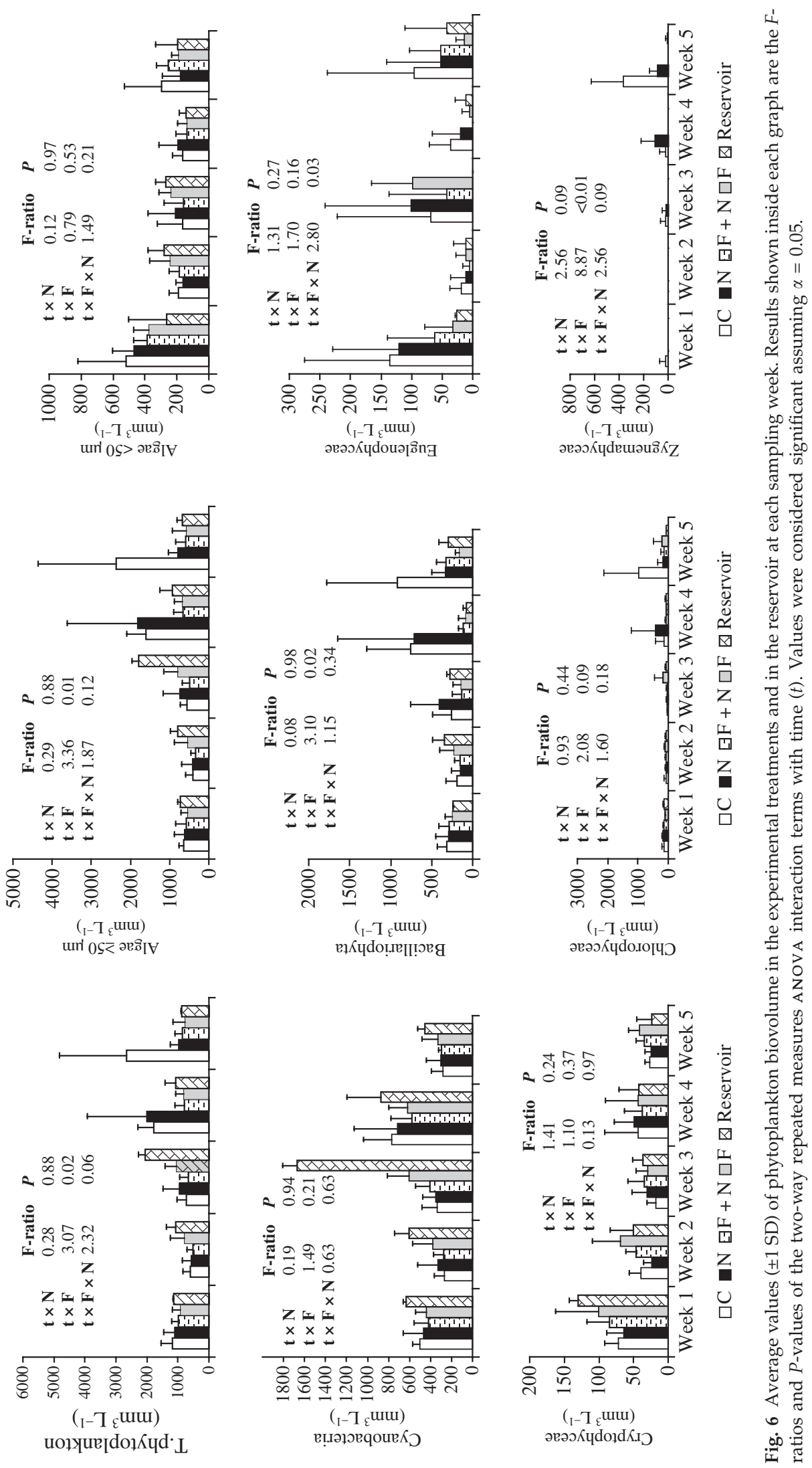


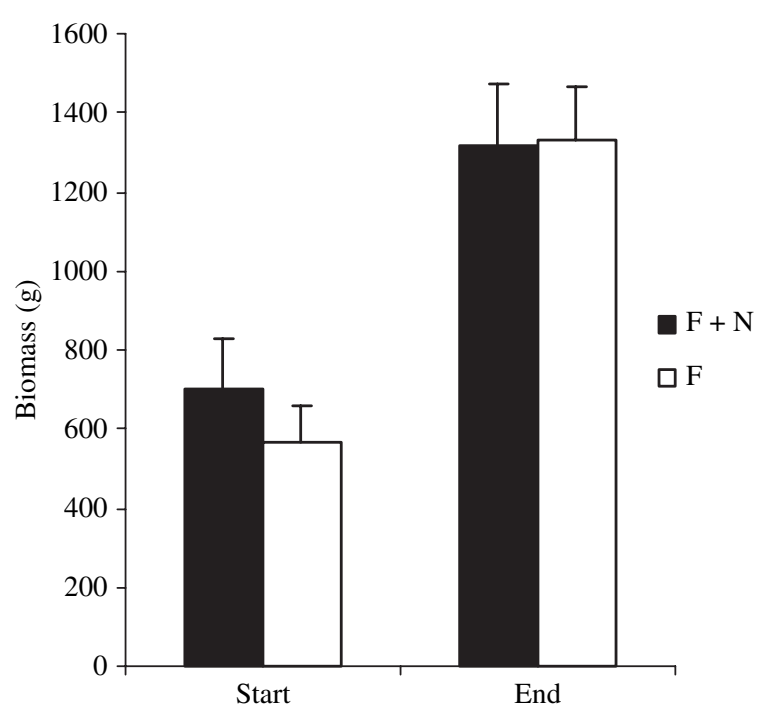

Fig. 7 Average biomass $( \pm 1$ SD) of tilapias per treatment at the start and end of the experiment in treatments with tilapias (F) and with tilapias plus nutrients additions $(\mathrm{F}+\mathrm{N})$.

omnivorous filter-feeding fish like tilapias. Filterfeeding fish may affect phytoplankton through grazing only when large algae account for a greater proportion of the total phytoplankton biomass as occurred in the present study. Otherwise, the effects of filter-feeding omnivorous fish would apparently not differ from those of zooplanktivorous fish. This study gives support to this hypothesis, but results from two other studies disagree. In two earlier studies, phytoplankton were dominated by colonial chlorophytes or filamentous cyanobacteria, but tilapia had no effect on the biomass of large algae (GALD $>50 \mu \mathrm{m}$ ) (Okun et al., 2008; Rondel et al., 2008).

As previously suggested the high initial concentrations of nutrients in the reservoir and in the mesocosms (created by local conditions prior to the experiment) may have affected the outcome of our experiment, leading to de-emphasis of the importance of nutrient loading relative to that of fish. The initial total phosphorus and total nitrogen concentrations in the reservoir and in the mesocosms were about 0.06 and $2.45 \mathrm{mg} \mathrm{L}^{-1}$ respectively, and remained relatively constant over the course of the experiment. The $\mathrm{TN}$ : TP ratios were always above $30: 1$, suggesting that limitation for nitrogen was unlikely (Huszar et al., 2006). Limitation of phytoplankton for light was also unlikely as the depth of the euphotic zone in the mesocoms, roughly estimated as 2.7 times the Secchi depth (Cole, 1994), was about the same as the mesocosms depth. The TN and TP concentrations in the reservoir and in the mesocosms are typical for reservoirs in the semi-arid region of Brazil (Sousa et al., 2008), and are also similar to those of other mesocosm experiments in semi-arid warm temperate lakes that have found significant nutrient effects on plankton communities (Fernández-Aláez et al., 2004; Romo et al., 2004). Therefore, high initial concentrations of nutrients in the reservoir may not be the only explanation for the lack of nutrients effects during our experiment.

The nutrient loading and fish stocking employed may have also affected the outcome of our experiment, leading to de-emphasis of the importance of nutrient loading relative to that of fish. However, our nutrient loading was within the range used in other mesocosm experiments manipulating nutrients and fish in six lakes across Europe (Stephen et al., 2004; Moss et al., 2004). The fish stocking densities used in our experiment $\left(120 \mathrm{~g} \mathrm{~m}^{-2}\right)$ were high compared to the aforementioned experiments, but still within the range found in another Brazilian reservoir (Starling et al., 2002). Moreover, a previous experiment involving manipulation of a gradient of stocking densities of tilapia revealed that the effects of tilapia on plankton were the same over a range of densities from 30 to $120 \mathrm{~g} \mathrm{~m}^{-2}$ (Okun et al., 2008). Therefore, we are confident that our results are not artifacts of our nutrient loading or fish stocking densities.

Instead, the lack of phytoplankton response to nutrient enrichment is consistent with a strong topdown control of fish grazing on phytoplankton. Under a strong grazing pressure from fish, the added nutrients did not accumulate in algal biomass and may have been lost to the sediment or sequestered by periphyton attached to the enclosure walls. By having access to feed on the sediment and on the periphyton growing on the walls, tilapia could benefit from nutrient enrichment and could exhibit enhanced growth in the treatment with nutrient addition. However, we found no significant effect of nutrient enrichment on tilapia growth, suggesting that tilapias were not a sink of the added nutrients. Unfortunately, we did not measure periphyton biomass or nutrient concentrations in the sediment during the experiment, but we observed that the periphyton layer on the walls of all enclosures was very thin after removing the mesocosms from the lake at the end of the experiment. Therefore, we believe that the added 
phosphates might have been lost to the sediment through co-precipitation with calcium carbonate precipitated from calcium bicarbonates dissolved in the water (Stumm \& Morgan, 1981) because the reservoirs in the region are characterised by very high carbonate alkalinity values (Bouvy et al., 2000). The added nitrates might have been lost through denitrification which should be high in the tropics (Lewis, 2000, 2002). Besides, the added nutrients may have also been transferred from the water column to the sediment through absorption by organic matter and/or adsorption to suspended sediment particles (Boström et al., 1988; Wetzel, 2001).

Food chain theory (Hairston, Smith \& Slobodkin, 1960; Fretwell, 1977; Oksanen et al., 1981; Carpenter et al., 1987; Persson et al., 1992) predicts that the response of phytoplankton biomass to nutrient enrichment depends on food chain length and might increase in the presence of zooplanktivorous fish while remaining unchanged in its absence. Conversely, food chain theory also predicts that zooplankton biomass might increase with nutrient enrichment in the absence of zooplanktivorous fish but remains relatively constant in the presence of zooplanktivorous fish. Our results confirm, to some extent, these predictions since rotifers but not phytoplankton biomass increased with enrichment in the absence of tilapias. However, the prediction that phytoplankton biomass might increase with enrichment in the presence of fish was not supported by our results because tilapia omnivory can exert a direct grazing control on phytoplankton that is not considered by theory. Hence, a major conclusion from our experiment is that current theory fails to predict the response of phytoplankton and zooplankton biomass to manipulations of omnivorous filter-feeding fish. Therefore, omnivory needs to be incorporated into the theory if we are to understand and predict the effects of fish manipulations on the structure and dynamics of pelagic food webs.

Finally, it has been suggested that nutrient control should be a greater priority than fish manipulation in the restoration of eutrophic shallow lakes in warm temperate regions (Moss et al., 2004; Stephen et al., 2004). However, our results show that the influence of fish on the plankton community and water transparency of a tropical eutrophic reservoir was significant and much stronger than that of nutrients. This suggests that manipulating the stocks of filter-feeding tilapi- as may be of importance for the water quality management of eutrophic reservoirs in tropical semi-arid regions.

\section{Acknowledgments}

We thank Edson Santanna for field assistance and Vanessa Mosca, Ana Catarina de Lima, Fabiana Araújo, Danyhelton Douglas, Rafael Freitas, Maria Marcolina Cardoso and Jandeson Brasil for assistance at the laboratory. We also thank the staff from IBAMA at ESEC Seridó for giving us access to the reservoir and the staff from DNOCS at the fish hatching station in Caicó for providing us with the fish used in the experiment. We thank Xavier Lazzaro, Michael Vanni and two anonymous reviewers for their suggestions to improve the manuscript. Funding was given by CNPq through the PELD Caatinga project.

\section{References}

APHA (1997) Standard Methods for the Examination of Water and Wastewater, 17th edn. APHA, Washington, DC.

Attayde J.L. \& Menezes R.F. (2008) Effects of fish biomass and planktivore type on plankton communities. Journal of Plankton Research, 30, 885-892.

Boström B., Andersen J.M., Fleischer S. \& Jansson M. (1988) Exchange of phosphorus across the sediment water interface. Hydrobiologia, 170, 229-244.

Bottrell H.H., Duncan A., Gliwicz Z.M., Grygierek E., Herzing A., Hillbricht-Ilkowska A., Kurasawa H., Larsson P. \& Weglenska T. (1976) A review of some problems in zooplankton production studies. Norwegian Journal of Zoology, 24, 419-456.

Bouvy M., Falcao D., Marinho M., Pagano M. \& Moura A. (2000) Occurrence of Cylindrospermopsis (Cyanobacteria) in 39 Brazilian tropical reservoirs during the 1998 drought. Aquatic Microbial Ecology, 23, 1327.

Brett M.T. \& Goldman C.R. (1997) Consumer versus resource control in freshwater pelagic food webs. Science, 275, 384-386.

Canonico G.C., Arthington A., Mccrary J.K. \& Thieme M.L. (2005) The effects of introduced tilapias on native biodiversity. Aquatic Conservation-Marine and Freshwater Ecostystems, 15, 463-483.

Carpenter S.R., Kitchell J.F., Hodgson J.R., Cochran P.A., Elser J.J., Elser M.M., Lodge D.M., Kretchmer D., He X. \& von Ende C.N. (1987) Regulation of lake primary 
productivity by food web structure. Ecology, 68, 18631876.

Chumchal M.M. \& Drenner R.W. (2004) Interrelationships between phosphorus loading and commom carp in the regulation of phytoplankton biomass. Archiv für Hydrobiologie, 161, 147-158.

Cole G.A. (1994) Textbook of Limnology. Waveland Press Inc, IL.

Datta S. \& Jana B.B. (1998) Control of bloom in a tropical lake: grazing efficiency of some herbivorous fishes. Journal of Fish Biology, 53, 12-24.

Diana J.S., Dettweiler D.J. \& Lin C.K. (1991) Effect of Nile tilapia (Oreochromis niloticus) on the ecosystem of aquaculture ponds, and its significance to the trophic cascade hypothesis. Canadian Journal of Fisheries and Aquatic Science, 48, 183-190.

Diehl S. (1993) Relative consumer sizes and the strengths of direct and indirect interactions in omnivorous feeding relationships. Oikos, 68, 151-157.

Drenner R.W., Smith J.D. \& Threlkeld S.T. (1996) Lake trophic state and the limnological effects of omnivorous fish. Hydrobiologia, 319, 213-223.

Drenner R.W., Gallo K.L., Baca R.M. \& Durward Smith J. (1998) Synergistic effects of nutrient loading and omnivorous fish on phytoplankton biomass. Canadian Journal of Fisheries and Aquatic Sciences, 55, 2087-2096.

Elhigzi F.A.R., Haider S.A. \& Larsson P. (1995) Interactions between Nile tilapia (Oreochromis niloticus) and cladocerans in ponds (Khartoum, Sudan). Hydrobiologia, 307, 263-272.

Fernández-Aláez M., Fernández-Aláez C., Bécares E., Valentin M., Goma J. \& Castrillo P. (2004) A 2-year experimental study on nutrient and predator influences on food web constituents in a shallow lake of north-west Spain. Freshwater Biology, 49, 1574-1592.

Fernando C.H. (1994) Zooplankton, fish and fisheries in tropical freshwaters. Hydrobiologia, 272, 105-123.

Figueredo C.C. \& Giani A. (2005) Ecological interactions between Nile Tilapia (Oreochromis niloticus) and phytoplanktonic community of the Furnas Reservoir (Brazil). Freshwater Biology, 50, 1391-1403.

Fretwell S.D. (1977) The regulation of plant communities by the food chains exploiting them. Perspective in Biology and Medicine, 20, 169-185.

Hairston N.G., Smith F.E. \& Slobodkin L.B. (1960) Community structure, population control, and competition. The American Naturalist, 94, 421-425.

Hambright K.D., Blumenhine S.C. \& Shapiro J. (2002) Can filter-feeding fishes improve water quality in lakes? Freshwater Biology, 47, 1173-1182.

Hansson L.-A., Annadotter H., Bergman E., Hamrin S.F., Jeppesen E., Kairesalo T., Luokkanen E., Nilsson P.-Å., Sondegaard M. \& Strand J. (1998) Biomanipulation as an application of food chain theory: constraints, synthesis and recommendations for temperate lakes. Ecosystems, 1, 558-574.

Hillebrand H., Dürselen C.-D., Kirschtel D., Pollinghter U. \& Zohary T. (1999) Biovolume calculation for pelagic and benthic microalgae. Journal of Phycology, 35, 403-424.

Huszar V.L.M., Caraco N.F., Roland F. \& Cole J. (2006) Nutrient-chlorophyll relationships in tropical-subtropical lakes: do temperate models fit? Biogeochemistry 79, 239-250.

Jeppesen E., Jensen J.P., Jensen C., Faafeng B., Hessen D.O., SØndergaard M., Lauridsen Brettum. \& Christoffersen K. (2003) The impact of nutrient state and lake depth on top-down control in the pelagic zone of lakes: a study of 466 lakes from the temperate zone to the Artic. Ecosystems, 6, 313-325.

Jeppesen E., Meerhoff M., Jakobsen B.A., Hansen R.S., Søndergaard M., Jensen J.P., Lauridesen T.L., Mazzeo N. \& Branco C.W.C. (2007) Restoration of shallow lakes by nutrient control and biomanipulation - the successful stratagy varies with lake size and climate. Hydrobiologia, 581, 269-285.

Lazzaro X. (1987) A review of planktivorous fishes: their evolution, feeding behaviors, selectivities, and impacts. Hydrobiologia, 146, 97-167.

Lazzaro X. (1997) Do the trophic cascade hypothesis and classical biomanipulation approaches apply to tropical lakes reservoirs? Verhandlungen Internationale Vereinigung fuer Theoretische und Angewandte Limnologie, 26, 719-730.

Lewis W.M. Jr (2000) Basis for the protection and management of tropical lakes. Lakes and Reservoirs Restoration and Management, 5, 35-48.

Lewis W.M. Jr (2002) Causes for the high frequency of nitrogen limitation in tropical lakes. Verhandlungen Internationale Vereinigung fuer Theoretische und Angewandte Limnologie, 28, 210-213.

Lu K., Jin C., Dong S., Gu B. \& Bowen S.H. (2006) Feeding and control of blue-green algal blooms by tilapia (Oreochromis niloticus). Hydrobiologia, 568, 111-120.

Lund J.W.G., Kipling C. \& Lecren E.D. (1958) The inverted microscope method of estimating algae number and the statiscal basis of estimating by counting. Hydrobiologia, 11, 143-170.

Margalef R. (1983) Limnologia. Editorial Ômega, Barcelona.

McQueen D.J., Post J.R. \& Mills E.L. (1986) Trophic relationships in freshwater pelagic ecosystems. Canadian Journal of Fisheries and Aquatic Sciences, 43, 1571-1581.

McQueen D.J., Johannes M.R.S., Post J.R., Stewart T.J. \& Lean D.R.S. (1989) Bottom-up and top-down impacts 
on fresh-water pelagic community structure. Ecological Monographs, 59, 289-309.

Meijer M.-L., de Boois I., Scheffer M., Portielje R. \& Hospe R. (1999) Biomanipulation in the Netherlands: an evaluation of 18 case studies in shallow lakes. Hydrobiologia, 408/409, 13-30.

Moss B., Stephen D., Balayla D.M. et al. (2004) Continental-scale patterns of nutrient and fish effects on shallow lakes: synthesis of a pan-European mesocosm experiment. Freshwater Biology, 49, 1633-1649.

Muller R. \& Weidemann O. (1955) Die Bestimmung des Nitrat-Ions in Wasser. Von Wasser, 22, 247.

Oksanen L., Fretwell S.D., Arruda J. \& Niemela P. (1981) Exploitation ecosystem in gradients of primary productivity. The American Naturalist, 118, 240-261.

Okun N., Brasil J., Attayde J.L. \& Costa I.A.S. (2008) Omnivory does not prevent trophic cascades in pelagic food webs. Freshwater Biology, 53, 129-138.

Pace M.L. \& Orcutt J.D. Jr (1981) The relative importance of protozoans, rotifers and crustaceans in a freshwater zooplankton community. Limnology and Oceanography, 26, 822-830.

Pace M.L., Cole J.J., Carpenter S.R. \& Kitchell J.F. (1999) Trophic cascades revealed in diverse ecosystems. Trends in Ecology and Evolution, 14, 483-488.

Perrow M.R., Meijer M.-L., Dawidowicz P. \& Coops H. (1997) Biomanipulation in shallow lakes: state of the art. Hydrobiologia, 342/343, 355-365.

Persson L., Diehl S., Johansson L., Andersson F. \& Hamrim S.F. (1992) Trophic interactions in temperate lake ecosystems - a test of food chain theory. American Naturalist, 140, 59-84.

Romo S., Miracle M.R., Villena M.-J., Rueda J., Ferriol C. \& Vicente E. (2004) Mesocosm experiments on nutrient and fish effects on shallow lake food webs in a Mediterranean climate. Freshwater Biology, 49, 1593-1607.

Rondel C., Arfi R., Corbin D., Le Bihan F., Ndour E.H. \& Lazzaro X. (2008) A cyanobacterial bloom prevents fish trophic cascades. Freshwater Biology, 53, 637-651.

Ruttner-Kolisko A. (1977) Suggestions for biomass calculation of plankton rotifers. Archiv für Hydrobiologie Beihefte Ergebnisse der Limnologie, 8, 71-76.

Sousa W., Attayde J.L., Rocha E.S. \& Eskinazi-Sant'Anna E. (2008) The response of zooplankton assemblages to variations in the water quality of four man-made lakes in semi-arid northeastern Brazil. Journal of Plankton Research, 30, 699-708.

Starling F., Beveridge M., Lazzaro X. \& Baird D. (1998) Silver carp biomass effects on the plankton community in Paranoa reservoir (Brazil) and an assessment of its potential for improving water quality in lacustrine environments. International Review of Hydrobiology, 83, 499-507.
Starling F., Lazzaro X., Cavalcanti C. \& Moreira R. (2002) Contribution of omnivorous tilapia to eutrophication of a shallow tropical reservoir: evidence from a fish kill. Freshwater Biology, 47, 2443-2452.

Stein R.A., DeVries D.R. \& Dettmers J.M. (1995) Foodweb regulation by a planktivore: exploring the generality of the trophic cascade hypothesis. Canadian Journal of Fisheries and Aquatic Sciences, 52, 2518-2526.

Stephen D., Balayla D.M., Bécares E. et al. (2004) Continental-scale patterns of nutrient and fish effects on shallow lakes: introduction to a pan-European mesocosm experiment. Freshwater Biology, 49, 1517-1524.

Stumm W. \& Morgan J.J. (1981) Aquatic Chemistry. John Wiley \& Sons, New York.

Turker H., Eversole A.G. \& Brune D.E. (2003) Filtration of green algae and cyanobacteria by Nile tilpia, Oreochromis niloticus, in the Partitioned Aquaculture System. Aquaculture, 215, 93-101.

Uhelinger V. (1964) Étude statisque des méthodes de dénobrement planctonique. Archives des Sciences, 17, 121-123.

Utermöhl H. (1958) Zur vervollkommung der quantitativen phytoplankton methodik. Mitteilungen Internationale Vereiningung fuer Theoretische und Angewandte Limnologie, 9, 1-38.

Valderrama J.C. (1981) The simultaneous analysis of total nitrogen and total phosphorus in natural waters. Marine Chemistry, 10, 109-122.

Vanni M.J. (2002) Nutrient cycling by animals in freshwater ecosystems. Annual Review of Ecology and Systematics, 33, 341-370.

Vanni M.J. \& Headworth J.L. (2004) Cross-habitat transport of nutrients by omnivorous fish along a productivity gradient: integrating watersheds and reservoir food webs. In: Food Webs at the Landscape Level (Eds Polis G.A., Power M.E. \& Huxel G.R.), pp. 43-61. University of Chicago Press, Chicago, IL.

Vanni M.J., Arend K.K., Bremigan M.T., Brunnell D.B., Garvey J.E., González M.J., Renwick W.H., Soranno P.A. \& Stein R.A. (2005) Linking landscapes and food webs: effects of omnivorous fish and watersheds on reservoir ecosystems. BioScience, 55, 155167.

Wetzel R.G. (2001) Limnology. Lake and River Ecosystems, 3rd edn. Academic Press, San Diego, CA.

Zambrano L., Martinez-Meyer E., Menezes N. \& Peterson A.T. (2006) Invasive potential of common carp (Cyprinus carpio) and Nile tilapia (Oreochromis niloticus) in American freshwater systems. Canadian Journal of Fisheries and Aquatic Sciences, 63, 1903-1910.

(Manuscript accepted 12 August 2009) 